\title{
An approach to designing vehicle routes in evacuation conditions
}

\author{
A. Polimeni, A. Quattrone \& A. Vitetta \\ Mediterranea University of Reggio Calabria, Italy
}

\begin{abstract}
In this paper what to models are considered in order to define optimal emergency vehicle distribution (in terms of vehicle numbers, weak users sequence to visit) and hence paths/routes with the objective to optimize the total time for safe users in evacuation condition. The design problem is tackled with a multilevel approach, which allows, by subsequent steps, to consider the network performances, the vehicle paths (One to One Problem) and the vehicle routes (Vehicle Routing Problem). In this paper the whole model is specified in terms of input and output variables and objective function.
\end{abstract}

Keywords: evacuation, emergency conditions, what to models.

\section{Introduction}

The network design problem can be treated using two different approaches: what if and what to [1]. In both cases the demand and the supply model are given. In the what if approach a specific configuration of the supply is also given. In both cases link flows can be calculated, as well as indicators of performance and impacts, deriving from a demand-supply interaction model, which are useful to evaluate the current solution. In the what to approach, there is a design model that generates and evaluates supply configurations by using information from previous explored solutions, considering both a set of objectives and a set of constraints. The route design for emergency vehicles can be tackled with a what to approach, in which the routes are the output of a multi-step process. The route design, or commonly Vehicle Routing Problem (VRP), is much discussed in literature $[2,3]$, but there are few papers in which it is connected with the network characteristics and link performances related to the demand $[4,5]$. 
This work is a part of the SICURO research project [6] carried out by the LAST-Laboratory for Transport Systems Analysis of the Mediterranean University of Reggio Calabria. The objective of the SICURO project is the development of models and guidelines for evacuation demand simulation [7], supply and demand-supply interaction simulation [8], supporting path design for emergency vehicles [9], and supporting urban transport planning in emergency conditions [10]. In a recent update $[11,12]$ the authors of this papers proposed an approach to simulate the evacuation demand in emergency conditions using dynamic models; in [13] and [14] a system of models and procedures is proposed for signal setting design in evacuation conditions; in [15] and [16] two classes of methods to compare evacuation plans are proposed.

Considering the path design for emergency vehicles, in [9] a model is reported to define a cost function that allows one to calculate the link (path) costs and then the best routes; in [17] some algorithms to find the shortest paths and to optimize the vehicle routes are reported; in [18] some tools to find the shortest paths and to optimize the vehicle routes are analyzed; in [19] a method to trace the emergency vehicles is reported.

In this paper a general design architecture for models is proposed to design the emergency vehicle routes. The proposed architecture has a multilevel structure that allows one to design the vehicle routes considering the system performances and the path choice. The proposed architecture is shown in section 2, which is divided into three subsections: the first describes the system performance estimation, in the second the path search problem is treated, in the third the routes design is reported. Finally, some conclusions are reported in section 3 .

\section{Design architecture}

To design the planning co-ordination $[20,21]$ of emergency vehicles, what to models are considered $[22,23]$. The what to approach is proposed in order to define optimal emergency vehicle distribution, in terms of vehicle number, weak users sequence to visit and hence paths/routes design to optimize an objective function (i.e. minimizing travel time and/or maximizing network reliability). The what to models allow interventions on the some supply characteristics (number of vehicles, position of the refuge areas), respecting some constraints (number of persons to save and sites to be left in). The models and the algorithms specified and calibrated in ordinary congested conditions cannot be applied to this particular case of congested and emergency conditions without new specifications and calibrations [24]. Analogous reasoning could be carried out with regard to the path choice models, relative to which is a large literature in the case of ordinary conditions [22] but only a few works [5, 25] are present in the particular case in which the conditions of a transport system are modified due to a disaster.

In literature two different approaches are developed: a simulation approach (what if), in order to simulate the operation of a transport system in which exogenously the supply and activity systems are defined [26]; and a design 
approach (what to), in order to intervene on the supply system optimizing some objectives respecting some constraints [27].

If the design problem is referred to the specific case of path design for emergency vehicles, two classes of users could be considered: the independent users who in disaster case follow the path of maximum perceived utility and the weak users who are brought in the refuge areas with emergency vehicles.

It is possible to generate the best paths/routes, which satisfy specific criteria, for the emergency vehicles that must rescue the weak users. The optimization problem in such case could be placed in the following terms:

- Objective: Minimize the emergency vehicle travel time.

- Variable: Paths/routes.

- Constraints: supply constraints, demand constraints, users-behavioural constraints, vehicles availability, and other constraints.

The problem can further be generalized considering also the network topology and capacity design (i.e. signal settings).

The design problem is tackled with a multilevel approach (figure 1); this approach can be summarized in three main steps:

1. system performances estimation, which can be achieved through one or a combination of the following: Traffic Assignment (TA) (static or dynamic), System Monitoring (SM) or Reverse Assignment (RA) [36];

2. One-to-One Problem (OOP) solution, which consists, given the costs on the network obtained by the previous step, in generating alternative paths for each origin-destination pair;

3. many-to-one problem solution or Vehicle Routing Problem (VRP), which consists, given the optimal paths between every origindestination pair obtained by solving the OOP, in the solution of a VRP formulated as a classic optimization problem whose objective is to calculate the best combination of one-to-one paths in order to visit a certain number of network nodes in succession.

The proposed approach has a structure that can be apply for designing the vehicle routes both in ordinary conditions and in emergency conditions. The difference between the two conditions (ordinary and emergency) is the modification in the equations linking the problem variables. These equations allow one to take account of changes in the transport system to the occurrence of the emergency (i.e. changes in supply and demand) in term of supply performances and users behaviours.

In the system the travel demand [28, 29] has two main components:

- ordinary demand $\mathbf{d}^{\mathrm{O}}$, is represented by the average flows of demand in the time slice $t$ considered; the element $\mathrm{d}_{\mathrm{t}, \mathrm{r}}^{\mathrm{O}}$ is the ordinary demand value related to the $r \mathrm{o} / \mathrm{d}$ pair;

- emergency demand $\mathbf{d}^{\mathrm{E}}{ }_{\mathrm{t}}$, is represented by the people present in the evacuation area in the slice time $t$; the element $\mathrm{d}_{\mathrm{t}, \mathrm{r}}^{\mathrm{E}}$ is the emergency demand value related to the $r \mathrm{o} / \mathrm{d}$ pair.

The emergency demand can be divided in two sub-components: 


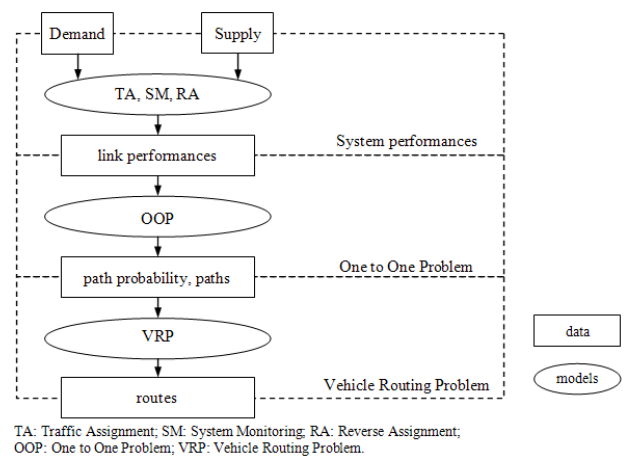

Figure 1: $\quad$ Multilevel procedure proposed.

- not controlled users and operators demand, $\mathbf{d}^{\mathrm{E}, \mathrm{NC}}{ }_{\mathrm{t}}$, that is the sum of users demand of evacuation people and operators that intervene for helping people and for save valuable goods without any real time information about system status;

- controlled operators demand, $\mathbf{d}^{\mathrm{E}, \mathrm{C}}$, that is operators that intervene for helping people and for save valuable goods with real time information about system status.

The demand components $\mathbf{d}^{\mathrm{O}}{ }_{\mathrm{t}}$ and $\mathbf{d}^{\mathrm{E}, \mathrm{NC}}{ }_{\mathrm{t}}$ move in the system with UE (User Equilibrium) approach: in the following we consider the vector $\mathbf{d}_{t}=\mathbf{d}_{t}{ }_{t}+\mathbf{d}^{\mathrm{E}, \mathrm{NC}}{ }_{\mathrm{t}}$. The demand component $\mathbf{d}^{\mathrm{E}, \mathrm{C}}{ }_{\mathrm{t}}$ moves in the system with SO (System Optimum) approach. This demand properties allow to consider two models for the demandsupply $[30,31]$ interaction: the first one is the UE assignment in which demand, path and link flows are mutually consistent with the costs that they induce; the second one is SO assignment, based on second principle of Wardrop (the condition under which the total cost in the network is minimum as expressed by the second principle of Wardrop is known as System Optimum (SO) [32]). Note that the demand $\mathbf{d}^{\mathrm{E}, \mathrm{C}}$ is much lower $\mathbf{d}_{\mathrm{t}}$, for this reason we can assume that the choices of users moving with the EU logic are not affected by users who move with the SO logic.

Below, the main features of the proposed approaches are provided. The following notation is used:

- $\quad \mathbf{b}^{\mathrm{E}, \mathrm{C}}$ controlled emergency vehicle capacity vector, with $\mathrm{b}^{\mathrm{E}, \mathrm{C}}{ }_{\mathrm{i}}$ the capacity for emergency vehicle $i$;

- $\quad \mathbf{g}_{\mathrm{t}, \mathrm{C}}$ emergency vehicle minimum path costs vector in the slice time $t$, with $\mathrm{g}_{\mathrm{E}, \mathrm{C}}$ t,k the cost for emergency vehicle on the path $k$;

- $\quad \mathbf{c}_{\mathrm{M}, \mathrm{t}}$ observed link costs vector in the slice time $t$, with $\mathrm{c}_{\mathrm{M}, \mathrm{t}, \mathrm{i}}$ the observed cost on the link $i$;

- $\quad \mathbf{c}_{\mathrm{t}}$, link costs vector in the slice time $t$, with $\mathrm{c}_{\mathrm{t}, \mathrm{i}}$ the cost on the link $i$;

- $\mathbf{f}^{\mathrm{E}, \mathrm{C}}$ emergency vehicle flow vector in the slice time $t$, with $\mathrm{f}_{\mathrm{t}, \mathrm{i}}^{\mathrm{E}, \mathrm{C}}$ emergency vehicle flow on the link $i$;

- $\quad \mathbf{f}_{\mathrm{t}}$ flow vector in the slice time $t$, with $\mathrm{f}_{\mathrm{t}, \mathrm{i}}$ the observed cost on the link $i$; 
- $\quad \mathbf{P}$ matrix of path choice probability, with $\mathrm{p}_{\mathrm{r}, \mathrm{k}}$ probability to choice the path $k$ related to the $r$ o/d pair;

- $\quad \Delta$ links-paths incidence matrix, with $\delta_{\mathrm{i}, \mathrm{k}}$ is equal to one if the link $i$ belong to path $k$, zero otherwise.

Moreover, all the symbols with "**" indicate the outputs (best values) of the considered model.

\subsection{System performances estimation}

In this section, the transport system simulation is analysed to evaluate their performances. The input consists in demand and supply, the output in flows and costs. Three methods may be used: TA, SM and/or RA (figure 2.a).

The TA problem (figure 2.b) such as the equilibrium or dynamic process models [32, 33], have the following input: a supply model, simulating how network performance; a demand model, simulating how user behaviour. It gives as output: link flows; link performance in terms of costs.

The TA problem can be solved with a static or dynamic approach; static assignment models simulate a transportation system in stationary conditions, reproducing the condition in which link flows and link costs are mutually consistent. The output is the link flow vector $\mathbf{f}$ and the link cost vector $\boldsymbol{c}(\mathbf{f})$.

Dynamic Traffic Assignment (DTA) models remove the assumptions of static models, allowing transportation system evolution to be represented. DTA models can be analysed as regards the characteristics of the link model adopted.

In particular, link flow representation can be continuous or discrete and cost functions can be aggregate or disaggregate. The output is the link flow vector for each time $t, \mathbf{f}_{\mathrm{t}}$, and the link cost vector, $\boldsymbol{c}_{\mathrm{t}}^{*}\left(\mathbf{f}_{\mathrm{t}}\right)$.

The user equilibrium assignment represent equilibrium configuration of the system, in which demand, path and link flow are mutually consistent the costs that they induce [32], that is the problem solution is a flow vector that, inserted in the assignment model, reproduces itself:

$$
\mathbf{f}_{\mathrm{t}}^{*}=\Delta \boldsymbol{P}\left(\mathbf{f}_{\mathrm{t}}^{*}\right) \cdot\left(\boldsymbol{d}_{\mathrm{t}}\left(\mathbf{f}_{\mathrm{t}}^{*}\right)\right)
$$

in which $\mathbf{f}^{*}, \mathbf{c}^{*}$ are defined for each time slice.

Note that in emergency conditions there is a change in demand, because the demand vector $\mathbf{d}_{t}$ is the sum of ordinary demand $\left(\mathbf{d}_{t}{ }_{t}\right)$ and evacuation notcontrolled demand $\left(\mathbf{d}_{\mathrm{t}}^{\mathrm{E}, \mathrm{NC}}\right)$.

The SM can be obtained with:

- measurement at fixed points in the network with traditional measurement systems like loop detectors and image processing [34];

- $\quad$ floating cars [35] in the network (individual cars, taxis, transit system vehicles).

SM costs and flows are usually made for a rate of network links. The output consists in the link flow vector $\mathbf{f}_{\mathrm{t}}$ and the link cost vector $\boldsymbol{c}_{\mathrm{t}}$ and/or the link flow vector for each time $t$ in a subset of links (figure 2.c). 


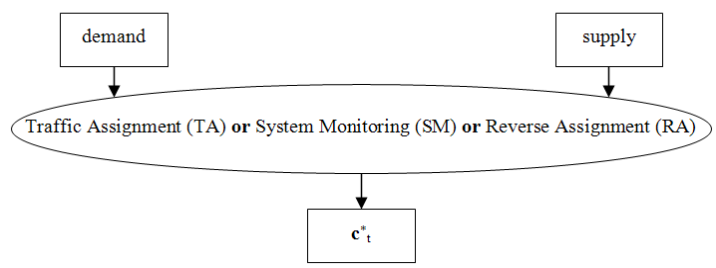

(a)

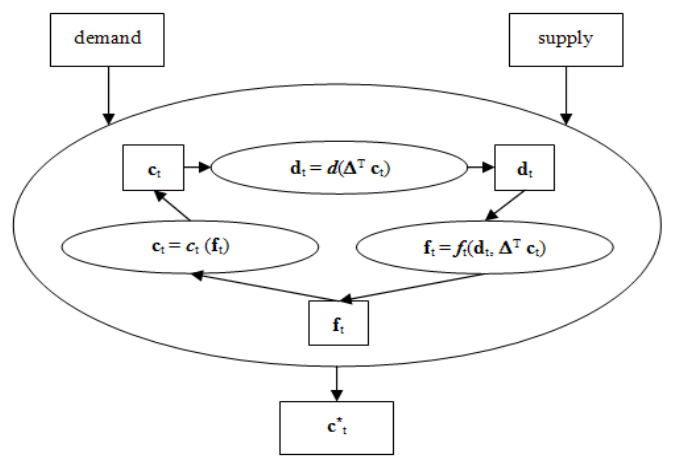

(b)
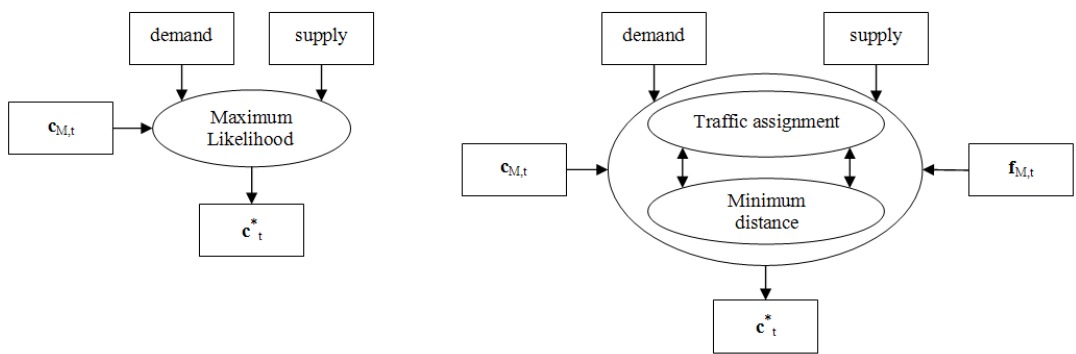

(c)

(d)

Figure 2: (a) System performances. (b) System performances: traffic assignment. (c) System performances: system monitoring. (d) System performances: reverse assignment.

Note the observed costs $\mathbf{c}_{\mathrm{t}}{ }_{\mathrm{t}}$ for a link subset, can be expressed as a sum of a mean cost $\mathbf{c}_{\mathrm{M}, \mathrm{t}}$ and a random residual $\boldsymbol{\varepsilon}_{\mathrm{t}}$ :

$$
\mathbf{c}_{\mathrm{t}}^{*}=\mathbf{c}_{\mathrm{M}, \mathrm{t}}+\boldsymbol{\varepsilon}_{\mathrm{t}}
$$

in which the variables are defined for each time slice $t$.

In particular, under suitable assumptions on $\varepsilon_{\mathrm{t}}$ distribution, the cost can be estimated with the maximum likelihood method. 
The RA models [36] have the following input:

- link flows;

- link performance in terms of costs;

and give as output

- the link cost parameters of the cost-flow functions used in the supply model;

- the value (number of trips) and/or the model parameters of the demand model.

In figure 2.d general flowchart for RA is reported, note that the TA is a subprocess of RA.

RA models, starting from observed costs and flows, supply the link cost parameters of the cost-flow functions used in the supply model, the value (number of trips) and/or the model parameters of the demand model. A mathematical formulation for RA is provided by [36]:

$$
\left(\mathbf{f}^{*}, \mathbf{c}^{*}{ }_{\mathrm{t}}\right)=\operatorname{argmin} z_{l}\left(\mathbf{d}_{\mathrm{t}}, \mathbf{d}^{*}{ }_{\mathrm{t}}\right)+z_{2}\left(\mathbf{f}_{\mathrm{t}}, \mathbf{f}_{\mathrm{t}}{ }_{\mathrm{t}}\right)+z_{3}\left(\mathbf{c}_{\mathrm{t}}, \mathbf{c}_{\mathrm{t}}{ }_{\mathrm{t}}\right)
$$

in which $\mathbf{f}_{\mathrm{t}}, \mathbf{c}_{\mathrm{t}}$ are defined for each time slice $t, z(\cdot)$ is a distance function between the observed values and the estimated values.

\subsection{One to one problem}

The one to one approach gives the probability of every path being chosen, from those perceived as admissible, between each origin to each destination.

The path search problem in the one-to-one approach, starting from the assumption that just a subset of all the possible topological paths (choice set) between an origin and destination is actually perceived by users, has been treated explicitly by distinguishing two different phases:

1. generation of a choice set, that explicitly identifies the possible alternatives;

2. path choice among the alternatives belonging to the choice set [22].

Regarding the choice set generation, there are different approaches in the literature; in an exhaustive approach, all the loop-less analytical paths on the network are available and belong to the single choice set for all users; in a selective approach, only some available paths represent attractive choice alternatives. The criteria used for choice set generation are treated in literature in several works. In the specific case of choice set generation for emergency vehicles the criteria which could be take into account are: to minimize the travel time and/or to maximize the network reliability.

In the emergency vehicles case, the path design can be defined as a System Optimum (SO) problem (figure 3). Indeed, considering that the emergency vehicles flow is much less than the total flow, the link costs (which depend on the total flow) can be considered not dependent by the controlled emergency vehicles flow.

The problem can be formulated as the minimization of the total cost of controlled emergency vehicles:

$$
\mathbf{f}_{\mathrm{E}, \mathrm{C}}^{\mathrm{E}}=\operatorname{argmin} \mathbf{c}_{\mathrm{t}}^{*}{ }_{(}^{\mathrm{T}}\left(\mathbf{f}_{\mathrm{t}}^{*}\right) \cdot \mathbf{f}^{\mathrm{E}, \mathrm{C}}{ }_{\mathrm{t}}
$$


subject to:

were:

$$
\sum_{i \in F S s} f_{t, i}^{E, C}+I_{s}=\sum_{i \in B S s} f_{t, i}^{E, C}+O_{s} \text { for each node } s
$$

$\mathrm{FS}_{\mathrm{s}}$ is the Forward Star of the node $s$ (the set of exit links from node s);

$\mathrm{BS}_{\mathrm{s}}$ is the Backward Star of the node $s$ (the set of entry links into node s);

$$
\begin{gathered}
\mathrm{O}_{\mathrm{s}}=\sum_{\mathrm{r}} \mathrm{d}_{\mathrm{t}, \mathrm{r}}^{\mathrm{E} C} \text { for each O/D pair } r \text {, with origin } s ; \\
\mathrm{I}_{\mathrm{s}}=\sum_{\mathrm{r}} \mathrm{d}^{\mathrm{E}, \mathrm{C}}{ }_{\mathrm{t}, \mathrm{r}} \text { for each O/D pair } r \text {, with destination } s .
\end{gathered}
$$

With this notation, if $s$ is not an origin of $\mathrm{O} / \mathrm{D}$ pair, $\mathrm{O}_{\mathrm{s}}$ is equal to zero; if $s$ is not a destination of $\mathrm{O} / \mathrm{D}$ pair $\mathrm{I}_{\mathrm{s}}$ is equal to zero.

Note the emergency vehicles demand vector, the SO give as output the emergency vehicles flow for each path and, implicitly, the paths followed for the controlled vehicles. The constraint establishes the flow conservation: users flows cannot be created or dispersed at any node of the network except origin/destination node.

\subsection{Many to one problem}

Concerning the many to one approach [9] problem can be formulated as a VRP. The VRP regards the necessity to visit a certain number of nodes in a given sequence (named route), leaving from an origin and returning to it, with the respect of some constraints (i.e. number of users to visit and their localization, number of vehicles and their capacity, and so on); the aim is to optimize an Objective Function (OF). The OF can depend on travel time, monetary cost or their combination.

The VRP can be solved with exact algorithms [37] or heuristic algorithms [4]. The literature that concerns the routing problems is very large, for study in depth see [2] and [3].

In the case of emergency vehicles, under ordinary conditions, in [38] is considered a fleet that intervenes in function of their current position on the network.

Under emergency conditions, [5] propose a model that simulates the variations in user path choice behaviour when, due to a calamitous event, the road network has limited accessibility. Liu et al. [39] to distribute medical

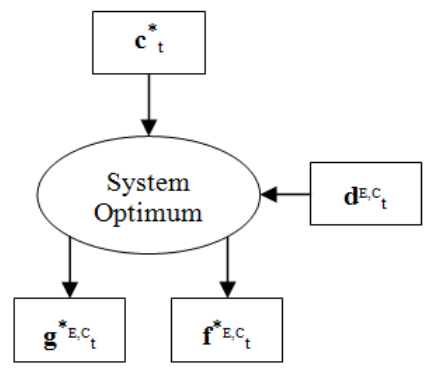

Figure 3: $\quad$ System Optimum approach for path optimization. 


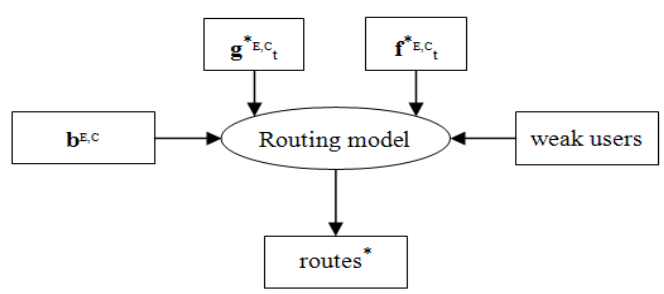

Figure 4: Approach for sequences optimization.

supplies and to respond at a large-scale emergency propose a VRP to minimize unmet demand and time delays. Shen et al. [40] propose a VRP to intervene in the case of large scale bioterrorism emergency. In [1] a methodology for the routing and dispatching of emergency vehicles in a disaster scenario is proposed.

As for path optimization, the VRP can be formulated as an optimum problem (figure 4). The objective is to calculate the vehicle routes minimizing a cost function which takes into account the problem characteristics and constraints.

The VRP formulation can be expressed as:

$$
\text { minimize } \mathbf{1}^{\mathrm{T}} \cdot \mathbf{\Xi}^{\mathrm{T}} \cdot \mathbf{g}^{\mathrm{E}, \mathrm{C}} \mathrm{t}
$$

subject to:

capacity constraints (for each vehicle $i$ the capacity $\mathrm{b}^{\mathrm{E}, \mathrm{C}}{ }_{\mathrm{i}}$ cannot be violated); congruence constraints (an user can not be reached more than once, all vehicles return to the starting point); time windows constraints; where $\Xi$ is the route-path incidence matrix, with $\mathrm{x}_{\mathrm{k}, \mathrm{K}}$ equal to 1 if the path $k$ belong to route $\kappa$, zero otherwise; $\mathbf{1}$ is an unit vector that has a number of rows equals to the number of routes.

\section{Conclusion}

In this paper an approach to routes design for emergency vehicles was discussed. The design problem was tackled with a multilevel approach, in which three aspects were considered: system performance estimation, One-to-One problem (OOP) solution, many-to-one problem solution (VRP).

Some methods (traffic assignment; real time cost measurement; reverse assignment) to analyse the system performances and define the flow and cost vectors were discussed. The path choice was analysed by considering an optimum problem that allows one to minimize the path costs.

The many-to-one problem was formulated as an optimization problem whose objective is to determine the best combination of one-to-one paths in order to visit a certain number of nodes (weak users) in succession.

In this paper the whole model was specified: for each level were defined the input and the output variables.

\section{References}

[1] Cantarella G. E., Pavone G. \& Vitetta A., Heuristics for urban road network design: lane layout and signal settings. European Journal of Operational Research, 175, pp. 1682-1695, 2006. 
[2] Laporte G., What You Should Know about the Vehicle Routing Problem. Les Cahiers $d u$ GERAD, G-2004-33, HEC Montreal, 2007. (www.gerad.ca/en/publications/cahiers.php)

[3] Gendreau M., Potvin J.Y., Bräysy O., Hasle G. \& Løkketamgen A., Metaheuristics for the vehicle routing problem and its extensions: a categorized bibliography, The vehicle routing problem: latest advances and new challenges (Golden B., Raghavan S., Wasil E., ed.), New York Springer, pp.143-169, 2008

[4] Ando N. \& Taniguchi E. (2006) Travel time reliability in vehicle routing and scheduling with time windows. Networks and Spatial Economics, 6, pp. 293-311.

[5] Takahashi N., K. Uchida, S. Kagaya \& M. Asano. Disaster impact analysis of limited access through traffic network model: the case of mt. Usu eruption. Proc. of the Eastern Asia Society for Transportation Studies, 5, pp. $2441-2453,2005$.

[6] Russo F. \& Vitetta A., Safety of users in road evacuation: General methodology and main results. Proc. of Urban Transport XIII, Urban Transport and the Environment in the 21st century, Brebbia C. A. (ed.), WIT Press, Southampton, pp. 763-772, 2007.

[7] Russo F. \& Chilà G., Safety of users in road evacuation: demand models. Proc. of Urban Transport XIII, Urban Transport and the Environment in the 21st century, Brebbia C. A. (ed.), WIT Press, Southampton, pp. 773$782,2007$.

[8] Vitetta A., Musolino G. \& Marcianò F.A., Safety of users in road evacuation: Supply and demand-supply interaction models for users. Proc. of Urban Transport XIII, Urban Transport and the Environment in the 21st century, Brebbia C. A. (ed.), WIT Press, Southampton, pp. 783-792, 2007.

[9] Vitetta A., Quattrone A. \& Polimeni A., Safety of users in road evacuation: design of path choice models for emergency vehicles. Proc. of Urban Transport XIII, Urban Transport and the Environment in the 21st century, Brebbia C. A. (ed.), WIT Press, Southampton, pp. 803-812, 2007.

[10] Russo F. \& Rindone C., Safety of users in road evacuation: planning internal processes and guidelines. Proc. of Urban Transport XIII, Urban Transport and the Environment in the 21st century, Brebbia C. A. (ed.), WIT Press, Southampton, pp. 825-834, 2007.

[11] Russo F. \& Chilà G., Dynamic approaches to demand model in evacuation conditions. Proc. of Urban Transport XVI, Urban Transport and the Environment in the 21st century, Brebbia C. A. (ed.), WIT Press, Southampton, pp. 303-312, 2010.

[12] Russo F. \& Chilà G., A sequential dynamic choice model to simulate demand in evacuation conditions. Proc. of Seventh International Conference on Computer Simulation in Risk Analysis and Hazard Mitigation, Brebbia C. A. (ed.), WIT Press, Southampton, 2010.

[13] Marcianò F. A., Musolino G. \&Vitetta A., A system of models for signal setting design of a signalized road network in evacuation conditions. Proc. 
of Urban Transport XVI, Urban Transport and the Environment in the 21st century, Brebbia C. A. (ed.), WIT Press, Southampton, pp. 313-323, 2010.

[14] Marcianò F.A., Musolino G. \& Vitetta A., Signal setting design on a road network: application of a system of models in evacuation conditions. Proc. of Seventh International Conference on Computer Simulation in Risk Analysis and Hazard Mitigation, Brebbia C. A. (ed.), WIT Press, Southampton, 2010.

[15] Russo F. \& Rindone C., Evaluation methods for evacuation planning. Proc. of Urban Transport XVI, Urban Transport and the Environment in the 21st century, Brebbia C. A. (ed.), WIT Press, Southampton, pp. 335-343, 2010.

[16] Russo F. \& Rindone C., Data Envelopment Analysis (DEA) for evacuation planning. Proc. of Seventh International Conference on Computer Simulation in Risk Analysis and Hazard Mitigation, Brebbia C. A. (ed.), WIT Press, Southampton, 2010.

[17] Vitetta A., Quattrone A. \& Polimeni A., Safety of users in road evacuation: algorithms for path design of emergency vehicles, Proc. of Urban Transport XIV, Urban Transport and the Environment in the 21st century, Brebbia C. A. (ed.), WIT Press, Southampton, pp. 727-737, 2008.

[18] Vitetta A., Quattrone A. \& Polimeni A., Safety of users in road evacuation: Modelling and DSS for paths design of emergency vehicles. Proc. of Sustainable Development and Planning IV, vol.1, Brebbia C. A. (ed.), WIT Press, Southampton, pp. 485-495, 2009.

[19] Polimeni A., Quattrone A. \& Vitetta A., A tool for tracing emergency vehicles during evacuation, Proc. of Urban Transport XVI, Urban Transport and the Environment in the 21st century, Brebbia C. A. (ed.), WIT Press, Southampton, pp. 325-333, 2010.

[20] Russo F. \& Rindone C., Safety of users in road evacuation: the logical framework approach in evacuation planning. Proc. of Urban Transport $X I V$, Urban Transport and the Environment in the 21st century, Brebbia C. A. (ed.), WIT Press, Southampton, pp. 751-760, 2008.

[21] Russo F. \& Rindone C., Safety of users in road evacuation: Modelling and DSS for LFA in the planning process. Proc. of Sustainable Development and Planning $I V$, vol.1, Brebbia C. A. (ed.), WIT Press, Southampton, pp. 453-464, 2009.

[22] Russo F, Vitetta A., An assignment model with modified Logit, which obviates enumeration and overlapping problems. Transportation, 30 (2), pp. 177-201, 2003.

[23] Cantarella G. E., Vitetta A. (2006) The multi-criteria road network design problem in an urban area. Transportation, 33(6), pp. 567-588.

[24] Russo F. \& Vitetta A., Risk evaluation in a transportation system. International Journal of Sustainable Development and Planning, 1 (2), pp. 170-191, 2006.

[25] Sumalee A. \& Kurauchi F., Network Capacity Reliability Analysis Considering Traffic Regulation after a Major Disaster. Networks and Spatial Economics, 6, pp. 205-219, 2006. 
[26] Sheffy Y. Urban transportation networks. Prentice Hall, Englewood Cliff, NJ, 1985.

[27] Magnanti T. L. \& Wong R.T., Network Design and Transportation Planning: Models and Algorithms. Transportation Science, 18, pp. 1-55, 1984.

[28] Russo F. \& Chilà G., Safety of users in road evacuation: RP vs. SP surveys in demand analysis. Proc. of Urban Transport XIV, Urban Transport and the Environment in the 21 st century, Brebbia C. A. (ed.), WIT Press, Southampton, pp. 703-713, 2008.

[29] Russo F. \& Chilà G., Safety of users in road evacuation: Modelling and DSS for demand. Proc. of Sustainable Development and Planning IV, vol.1, Brebbia C. A. (ed.), WIT Press, Southampton, pp. 465-474, 2009.

[30] Vitetta A., Musolino G. \& Marcianò F. A., Safety of users in road evacuation: calibration of cost functions and simulation. Proc. of Urban Transport XIV, Urban Transport and the Environment in the 21st century, Brebbia C. A. (ed.), WIT Press, Southampton, pp. 715-725, 2008.

[31] Vitetta A., Musolino G. \& Marcianò F.A., Safety of users in road evacuation: Modelling and DSS for transport supply and supply-demand interaction. Proc. of Sustainable Development and Planning IV, vol.1, Brebbia C. A. (ed.), WIT Press, Southampton, pp. 475-484, 2009.

[32] Cascetta E., Transportation systems engineering: theory and methods. Springer Netherlands, 2001.

[33] Wardrop J. P. Some theoretical aspects of road traffic research. Proc of the Institute of Civil Engineers, Part II (1), pp. 325-378, 1952.

[34] Hoose N., Computer image processing in traffic engineering, New York: John Wiley \& Sons, Inc., 1991.

[35] Torday A. \& Dumont A.G., Probe vehicles based travel time estimation in urban networks. Proc. of TRISTAN V, 2004.

[36] Russo F. \& Vitetta A., Reverse assignment: Updating demand and calibrating cost jointly from traffic counts and time measurements, Proc. of International Symposium on Transportation and Traffic Theory, Maryland University, 2005.

[37] Qureshi A.G., Taniguchi E. \& Yamada T., An exact solution approach for vehicle routing and scheduling problems with soft time windows. Transportation Research Part E, 45, pp. 960-977, 2009.

[38] Yang S., Hamedi M., Hagani A., Online Dispatching and Routing Model for Emergency Vehicles with Area Coverage Constraints. Transportation Research Record: Journal of Transportation Research Board, 1923, 2005.

[39] Liu D., Han J. \& Zhu J., Vehicle routing for medical supplies in large scale emergencies. Proc. of the first international symposium on optimization and systems biology, Beijing, China, August 8-10, 2007.

[40] Shen Z., Dessouky M. \& Ordóñez F., The stochastic vehicle routing problem for large scale emergencies, 2007. Document available at: http://www-rcf.usc.edu/ maged/publications/routing4LSE.pdf

[41] Jotshi A., Gong Q. \& Batta R., Dispatching and routing of emergency vehicles in disaster mitigation using data fusion. Socio-Economic Planning Sciences, 43, pp. 1-24, 2009. 